\title{
Identidade cultural relida: leitura e memória coletiva no romance O outro pé da sereia de Mia Couto
}

\author{
Reinterpreted cultural identity: reading and collective memory \\ in the Mia Couto's novel O outro pé da sereia
}

\author{
MARCELO FRANZ ${ }^{1}$ \\ VICTOR DE BARROS RODRIGUES 2 \\ 'Universidade Tecnológica Federal do Paraná (UTFPR). Curitiba, PR, Brasil. \\ ${ }^{2}$ Universidade Federal do Paraná (UFPR). Curitiba, PR, Brasil.
}

\begin{abstract}
Resumo: Analisamos a representação do ato leitor na obra O Outro Pé da Sereia (2006), de Mia Couto. O romance entende a leitura como veículo de reprocessamento da memória coletiva, termo que abordaremos sob a ótica de Maurice Halbwachs (2006). Dividida em duas épocas, (situadas nos anos de 2002 e 1560) a ação romanesca se centra na viagem realizada pela protagonista, Mwadia até sua comunidade de origem a fim de abrigar a estátua de uma santa com um dos pés arrancados, encontrada às margens de um rio. Junto com a imagem, ela encontrou documentos que descrevem a expedição do jesuíta D. Gonçalo para difusão do Catolicismo na África no século XVI. O contato com esses objetos resulta na recuperação e ressignificação de experiências passadas, a partir dos conteúdos lidos. Isso redefine a própria individualidade de Mwadia e sua relação com a comunidade.
\end{abstract}

Palavras-chave: memória; leitura; Mia Couto.

\begin{abstract}
This paper analyzes the representation reading in the Mia Couto's novel $O$ outro pé da sereia (2006), Mia Couto. The novel understands reading as reprocessing vehicle of collective memory, a term which will be discussed from the perspective of Maurice Halbwachs (2006). Divided in temporal plots, situated in 2002 and 1560, the novelistic action focuses on the journey of the protagonist Mwadia till her community of origin in order to shelter the statue of a saint without one foot that was found on the banks of a river. Along with the image, she founds some documents that described the D. Gonçalo's expedition to spread Catholicism in Africa in the sixteenth century. The contact with these objects results in the recuperation and resignification of past experiences. The reading content redefines Mwadia's individuality and relation with the community.
\end{abstract}

Keywords: memory; reading; Mia Couto.

\section{Introdução}

A representação do ato leitor, com vasta tradição na história da literatura, é, a nosso ver, um dos elementos temáticos mais destacados no romance $O$ outro $p$ é $d a$ sereia (2006), do escritor moçambicano Mia Couto. Com efeito, junto com a complexidade estrutural do enredo, que embaralha tempos e contextos, sobrepondo o ficcional ao histórico, chama-nos a atenção a forma como o texto representa a experiência leitora da protagonista Mwadia, considerando que o seu "ler" envolve, como veremos, o contato tanto com a matéria escrita quanto com a matéria imagética. Em qualquer dos casos, essas leituras acionam na personagem uma releitura da sua memória, seja a individual seja a coletiva, propiciando-lhe, pelo seu empenho "ressignificador" dos textos e objetos lidos, uma ressignificação de sua identidade pessoal e cultural.

Como acontece nas mais fundas vivências do que lemos, mais do que ler, talvez Mwadia seja "lida" pelo que lê, vivenciando um processo de interação que pressupõe reconhecimento e recusa. Além disso, é significativo que sua leitura se dê em paralelo com - ou no transcurso de - uma viagem. A polissemia desse deslocamento, que ata pontos dispersos de sua história pessoal, tem como nó a travessia pelos universos lidos. 
Caberia nos determos, inicialmente, em algumas coordenadas teóricas orientadoras de nossa reflexão sobre memória e sobre leitura.

\section{Leituras da memória, leituras da história}

As numerosas e variadas representações ficcionais contemporâneas da memória costumam direcionar o olhar do estudioso para a inevitável problematização das "formas do dizer" da memória, feita da complexa simbiose das memórias individuais e das coletivas. De fato, se é verdade que em muitos casos o texto literário propõe o encaminhamento de sua exegese ora na direção das "viagens íntimas", ora na das "aventuras na história", é muito corrente, sobretudo na ficção dos últimos tempos (em que prevalece a problematização do sujeito e do discurso que o "realiza"), o cruzamento de ambas. Assim, a representação da subjetividade oscila entre o compromisso com a historicidade (no desenho possível de um sujeito histórico) e as fragilidades advindas da construção artística de um ser que existe pelo ato narrativo e pela rememoração (no perfil traçado de um sujeito pessoal). O resultado inevitável disso é a relativização de qualquer representação do memorialístico, importando mais que tudo, a quem lê esse memorialismo ficcional investigar a enunciação do lembrar e suas condições de realização.

O sociólogo Maurice Halbwachs define as diferentes vertentes do termo memória (memória coletiva, memória pessoal e memória histórica) a partir do estabelecimento das relações sociais. Segundo o estudioso, a lembrança subjetiva não existe sem a memória coletiva. A própria forma como selecionamos e nos comportamos diante das nossas lembranças mais íntimas seria, por essa medida, definida pelo nosso pertencimento a uma memória do grupo. Para Halbwachs:

Se a memória coletiva tira sua força e sua duração por ter como base um conjunto de pessoas, são os indivíduos que se lembram, enquanto integrantes do grupo. [...] cada memória individual é um ponto de vista sobre a memória coletiva, que este ponto de vista muda segundo o lugar que ali ocupo e que esse mesmo lugar muda segundo as relações que mantenho com outros ambientes (HALBWACHS, 2006, p. 69).

O autor salienta o aspecto coletivo da memória, que encontra principalmente na linguagem o seu instrumento socializador. É por meio da linguagem que os membros de determinado grupo trocam experiências e são sociáveis por partilharem de pensamentos e ideias em comum (HALBWACHS, 2006, p. 76). A memória coletiva é formada a partir de uma relação de aceitação de pertencimento a um grupo, sendo que ela contém as memórias individuais, mas não se confunde com essas. Não haveria, segundo essa tese, possibilidade de existência de uma memória exclusivamente individual, pois as lembranças se inserem em relações sociais, e não se restringem a vivências isoladas. A memória coletiva se beneficia de experiências que resultam numa espécie de acervo de lembranças que, quando compartilhadas, são o real conteúdo da cultura do grupo. A memória individual, então, pode ser entendida como o resultado de diferentes influências sociais que se articulam entre si.

De certo modo, a leitura é um exemplo prático do jogo entre o lembrar pessoal e a memória do(s) grupo(s) a que pertencemos. Complementar à descrição do memorialístico feita por Halbwachs, a reflexão de Vincent Jouve sobre a leitura nos permite ver, numa linha de consonância, que o leitor individual, ao ressignificar o lido, restabelece vínculos com a memória de seu grupo cultural, sendo a leitura a vivência da rememoração de leituras anteriores originadas do coletivo (JOUVE, 2002). Em suma não há composição textual pelo autor sem que se ative uma rede de memórias do já criado (que é relido). Não há produção de sentido pela recepção sem que se ative uma rede de memórias do lido (que é recriado).

Para os interesses desse estudo, cumpre ressaltar a relação entre memória e leitura. Nas culturas que se afastaram do estágio do "agrafismo" (que também não deixa de propor narrativas que se apresentam à "leitura"), o acesso à memória do coletivo se dá em grande medida por meio de textos que, em diferentes direções, sistematizam e erigem essa memória. Desse modo, a vivência realizadora de sentido dos textos da comunidade (sendo que esses textos se encarregam de construir a identidade do coletivo) constitui a identidade pessoal dos leitores na sua relação com a memória do grupo. Mas as comunidades ágrafas - como é o caso de muitas que habitam o continente africano - também estabelecem sofisticadas relações com os "textos" formadores da memória coletiva pela "leitura" que deles se faz.

José de Souza Miguel Lopes define a cultura moçambicana como essencialmente acústica: "Designo por cultura acústica a cultura que tem no ouvido e não na vista, seu órgão de recepção e percepção por excelência" (LOPES, 2002, p. 267). As culturas acústicas têm como base a oralidade e relacionam-se estritamente com a memória e com os procedimentos por ela disponibilizados. Os limites de memória determinam a criação de vários recursos para a conservação da cultura. Um dos principais meios utilizados pelo discurso oral é a repetição, que se desenvolve de maneira linear e é irreversível na cadeia do tempo, não permitindo revisão. Com os recursos de sua memória de longo prazo empregados para reter e transmitir as representações que lhes parecem dignas de perdurar, os membros das culturas acústicas exploram ao 
máximo o único instrumento de inscrição de que dispõem (LOPES, 2002, p. 273).

Não raro, escritores africanos de países que passaram por processos de descolonização marcados pela guerra, como é o caso de Moçambique, elegem como centro estético - e crítico - de sua arte a conciliação de uma cultura oral nativa (que, por razões identitárias, buscam exaltar) e uma língua europeia em que escrevem. É o que se vê nos romances de Mia Couto.

É de memória e de leitura que, em linhas gerais, trata O Outro Pé da Sereia. Caberia recuperar alguns incidentes do enredo a fim de melhor situar essas ocorrências. O romance passeia por contextos históricos, políticos e sociais distintos, que têm como espaço principal a terra natal do escritor, Moçambique. A ação transcorre em duas épocas diferentes, num interessante jogo de sobreposição de tempos intercalados ao longo dos capítulos, o que induz à leitura dos reflexos do passado nos dias atuais: num primeiro plano, temos a ação posterior ao fim da guerra civil de Moçambique, em 2002, com a reestruturação de um país sedento por uma identidade própria reconhecida. Num segundo plano, a ação é situada no momento da colonização portuguesa no continente africano, em 1560, quando o religioso D. Gonçalo da Silveira é enviado com a missão de catequizar e converter do rei de Monomotapa, mirando os benefícios disso para o projeto de dominação da região pela Coroa Portuguesa.

$\mathrm{Na}$ história de 2002, o enredo gira em torno da personagem Mwadia Malunga cujo nome tem origem na língua si-nhungwé falada no noroeste de Tete, em Moçambique, e significa "canoa". Sua aventura se inicia quando ela, junto com seu marido, Zero Madzero, encontra nas margens de um rio, próximo do lugar onde vivem (curiosamente chamado de Antigamente) diários de uma viagem de navegação portuguesa dos tempos de colonização, juntamente com uma imagem de Nossa Senhora com um dos pés arrancado. Intrigada e comovida, Mwadia se impõe a missão de providenciar um destino para a Santa e, para isso, retorna a sua cidade de origem, Vila Longe, a qual havia abandonado anos antes para viver com seu marido e para onde não retornara.

A segunda história é uma narrativa histórica que conta como a imagem de Nossa Senhora - a mesma que Mwadia encontrou mais de 400 anos depois - chegou a Moçambique, vindo na embarcação portuguesa Nossa Senhora da Ajuda, em 1560, sob os cuidados de D. Gonçalo da Silveira, que viajava junto com outros tantos marinheiros e escravos a serviço dos interesses de colonização do império de Portugal. Nesse plano de ação, um dos pontos mais importantes é o modo como a imagem de Nossa Senhora é venerada pelo escravo Nimi Nsundi, prisioneiro capturado na costa do Congo, supostamente cristianizado, que servia aos portugueses na viagem.
Para Nsundi - que tem o acesso à Santa autorizado pelos religiosos da embarcação, que o veem apenas como um pacífico africano convertido - a imagem é ressignificada e, em seu culto, assume a representação da deusa Kianda (nomeada de Nzuzu na tradição moçambicana), uma deusa das águas. Segundo Nsundi, "O que sucedeu é que a nossa deusa ficou prisioneira na estátua de madeira dos portugueses" (COUTO, 2002, p. 208). Nessa ressignificação, proporcionada pelo sincretismo religioso, a imagem da Santa (cujo culto "blasfemo" resultará numa severa punição a Nsundi) é, simbolicamente, o elo capaz que ligar passado e presente, unindo também, pelo seu conteúdo místico, povos distantes.

É inegável a importância do diálogo com os temas - e os textos - da história para o romance de Mia Couto. Sua leitura do histórico (e do historiográfico) pode ser entendida na mesma chave interpretativa da sua vinculação às correntes da literatura pós-colonial. Os autores identificados com essa tendência se valem da língua do colonizador para expressar o discurso do colonizado, sem negar a influência que o dominador exerceu em sua cultura. Com isso surgem as vozes de minorias historicamente excluídas (índios, negros e mulheres, homossexuais) falando de si e de sua cultura, construindo um discurso de afirmação identitária que se alimenta, por um lado, da memória do que as rebaixou e, por outro, de uma intenção de revisão dos conceitos formados pelo rebaixamento de que foram vítimas, daí a necessidade da composição de uma história revista à luz dessa agenda de reparação.

Em uma sociedade pós-colonial, a questão do reencontro com o passado é algo tão desejado quanto inevitável, uma vez que a carga de ressentimentos alimentados durante o período da dominação pede o constante olhar para esse passado a fim de evitar que ele se repita. Porém, para as comunidades dominadas, voltar ao passado é não só se reencontrar seus mitos, crenças e cultura, mas também se reconstruir, com as influências inegáveis do contato com o dominador, e a partir daí encontrar uma identidade que, baseada na visita à memória coletiva, seja útil a um projeto de futuro, o que em muitos casos chega a soar "utópico" em vista da precariedade material advinda quer da colonização, quer da luta contra ela. Algo disso se vê atualmente em Moçambique

Sabe-se que a colonização obrigou o povo moçambicano a se adaptar à religião imposta pelo império Português, o Cristianismo. O povo foi obrigado a abandonar costumes milenares e se adequar a uma nova realidade. Os "nyangas", curandeiros ou feiticeiros, foram proibidos de realizar qualquer tipo de ritual.

Quando o colonizador impede manifestações religiosas do colonizado está constituindo com violência 
uma defesa de si e de sua ideologia. Mas, apesar de todas as proibições impostas, alguns grupos étnicos de Moçambique continuaram a manter suas crenças de forma subversiva, e a partir disso, estabeleceram relações sincréticas com os santos católicos. A igreja adaptava os mitos cristãos para se aproximar dos nativos e obter conversões. Essas relações sincréticas, ao invés de levarem o povo a seguir uma nova religião, em muitos casos ajudaram a manter a crença nos deuses e mitos tradicionais. Assim as religiões africanas sobreviveram aos tempos de colônia (PARADISO, 2010).

A temática do religioso é sempre presente nas obras de Mia Couto. Pode-se dizer que a busca do povo africano por sua identidade, para além as visões eurocêntricas estereotipadas e cristalizadas, é um dos centros de sua criação literária. As vivências de suas personagens frequentemente se centram na definição de suas identidades - aí incluída a religiosidade - em face do coletivo, e o recurso ao histórico é, em $O$ Outro Pé da Sereia, uma forma complexa de se chegar a isso. Mas o conceito de história para Couto, no modo como ele a ficcionaliza, corre ao largo da discussão sobre a verdade dos fatos historiados. Suas narrativas não pretendem a expressão de "realidades" e sim a compreensão (mediada pelas palavras e sua capacidade de (re) invenção) dos incidentes da história.

Observando a forte e variada presença na literatura pós-moderna de revisões do histórico, a estudiosa Marilene Weinhardt salienta que a ficção não é uma concorrente da história. Além disso, segundo ela, há uma diferença de base entre o processo utilizado pelo ficcionista (definido como "meta-historiador") e o estudioso da história. O ficcionista se dá a um trabalho que "é dedutivo, impondo uma forma a seu objeto, em função da qual o escolhe". Já a criação do historiador implica um processo que é "indutivo, a forma sucedendo a pesquisa" (WEINHARDT, 2002, p. 107)

Por não exigir veridicalidade, a literatura se fixa como o campo onde a memória poderá ser livre, seguindo caminhos desprendidos da restrição criativa que a história impõe. Em textos ficcionais que se referem à realidade histórica (notadamente o romance histórico), é sempre tênue a distinção entre história e estória, já que, segundo Antoine Compagnon, a linguagem ficcional está sempre no limite entre uma representação carregada do senso de abstrato e o que vemos como referente real, ou seja, a escrita ficcional é oriunda de uma realidade concreta exterior que, por sua vez, é transfigurada pelo artista da palavra (COMPAGNON, 2010, p. 51).

No livro de Mia Couto, a reconstrução ficcionalizada da história se liga ao conceito de memória, termo que, seja no plano individual, seja no coletivo, refere-se à faculdade de reter ideias e sensações e também, segundo o filósofo Paolo Rossi, a uma realidade de alguma forma intacta e contínua. É de se ressaltar que por meio do compartilhamento de vivências do passado relembradas no presente, contribui-se para a formação de um "sentimento de pertinência a um grupo de passado comum, que compartilha memórias" (KESSEL, 2012, p. 3), ou para a formação de uma identidade própria. Paolo Rossi afirma: "A memória tem algo a ver não só com o passado, mas também com a identidade e, com a própria persistência no futuro" (ROSSI, 2010, p. 24).

Deve-se considerar também que a memória é seletiva e variável, pois é próprio dela (seja de modo intencional, seja pelos meandros do inconsciente) registrar somente vivências que se tornarão parte do acervo identitário de determinado sujeito ou grupo. No plano coletivo, é essa seleção - estabelecida tanto pela dinâmica social como pelo substrato simbólico do grupo - que decide o que é relevante o suficiente para ser rememorado de geração a geração e o que deve ser esquecido, sendo, portanto, o ato de "lembrar" tão importante quanto o ato de "esquecer". No plano das experiências sociais, o que se denomina "cultura" está intimamente relacionado ao conceito de memória coletiva construída pelo complexo balanço entre o esquecer e o lembrar daquilo que forma um grupo social.

\section{A representação do ler}

De acordo com Marisa Lajolo e Regina Zilberman, em A Formação da Leitura no Brasil (1996), a representação do leitor pelo texto ficcional é um elemento contribuinte para se pensar uma história social da escrita. Nas palavras das autoras, tematizar a leitura é dar "lugar privilegiado para o tecimento desta história não só por representá-la ou questioná-la, mas, principalmente, por tecê-la a partir da linguagem em que se criam tais leitores de papel e tinta" (LAJOLO e ZILBERMAN, 1996, p. 54).

Um modo clássico de representação literária do leitor é aquele em que se procede a ficcionalização, no enredo do romance, de um ato de leitura, sendo a personagem protagonista caracterizada, entre outras coisas, mas com grande destaque, como alguém que lê e tem sua vida marcada por isso. É o que se vê na descrição de figuras como Alonso Quijano (Dom Quixote, de Miguel de Cervantes), Emma Bovary (Madame Bovary, de Gustave Flaubert), Policarpo Quaresma (Triste fim de Policarpo Quaresma, de Lima Barreto) e Visconde de Sabugosa (Sítio do Pica-Pau Amarelo, de Monteiro Lobato). Nos enredos protagonizados por personagens leitores, o texto se reporta à experiência de uma leitura já feita e os impactos que ela pode ter tido em quem a fez.

A série das obras que se deram a isso é longa e, em alguns casos, como no do Dom Quixote, de Cervantes, 
oferecem, a partir da ficção, importantes contribuições para se pensar sobre o papel da leitura na vida individual uma vez que se representam cenas de leitura - e suas consequências - para que o receptor identifique no texto uma situação que pode se reproduzir na sua experiência. Assim, representar, imagens de atos de leitura pode ser lido como uma estratégia autoral metalinguística de desautomatização da leitura, convidando o leitor empírico a que repense o processo material e vivencial do que lê. O texto literário não apenas traz implícito seu leitor pressuposto, mas o representa, em atos de leitura que, ao serem desdobrados e reinventados pelo leitor real, podem provocar ou problematizar os modos como se dá a sua relação com a leitura literária.

Mas essa modalidade de retrato do leitor e da leitura, no que tem de metaliterário, também pode se abrir a discussões como a da construção do significado, as condições concretas da experiência leitora, situadas contextualmente e ficcionalizadas pelas obras, os suportes e ambientes de leitura, servindo também para ilustrar aspectos históricos dos atos de leitura ou as diferentes visões da sociedade - retratadas literariamente - sobre esses atos. (LAJOLO e ZILBERMAN, 1996, p. 14-56).

Como vimos, em O Outro Pé da Sereia, o elemento deflagrador dos conflitos da ação é a relação que a protagonista Mwadia passa a ter com os objetos encontrados à margem do rio: a Santa com um pé arrancado e os escritos do século XVI que contam da expedição de padres jesuítas que tinha por objetivo abordar populações das margens do rio Monomotapa. Nesses escritos apresentam-se, ao entendimento da leitora, as vivências, conflitos, amores e dramas de exploradores, religiosos, escravos e agregados que, na euforia do ciclo das viagens de descobrimento, viam na África tanto a riqueza como o perigo, a atração e o medo, numa experiência do choque cultural.

Em sua leitura, com as consequências advindas disso, Mwadia, ao ter contato com os papéis datados de 1560 , passa a recuperar, narrar e, por fim, vivenciar as experiências passadas. Assumindo um papel recriador dos relatos dos viajantes - que seriam mortos pelos nativos -, a personagem revivencia e ressignifica os conteúdos lidos, revisitando a história de seus antepassados, sobretudo nos momentos em que reconta os conteúdos de sua leitura, fazendo os seus ouvintes entenderem que ela "incorpora" (num transe) o espírito dos antepassados.

\section{Textos lidos, imagens lidas}

O termo latino legere, forma antecessora do verbo ler, denominava o ato de colher e armazenar. Ler é uma operação de percepção, de identificação e de memorização de signos (JOUVE, 2002, p. 17).
Trata-se de uma atividade complexa de interpretação capaz de provocar diversos tipos de emoções a quem se dá a tal experiência. Assim como a memória coletiva, a leitura é formadora de identidades, pois o leitor não pode ser visto somente como quem cria os sentidos da leitura, mas também como alguém que se forma por esses sentidos. O leitor amplia seu acervo a cada nova leitura e, como todo texto se alimenta de outro, torna-se impossível ler algum sem, mesmo que inconscientemente, relacioná-lo com experiências de vida e com leituras passadas. Dessa forma, o ato leitor é memorialístico em essência, já que, por um lado, se operacionaliza ora como recurso, ora como constituinte, de um "acervo" e, por outro, nos liga a camadas de memória dos sentidos lidos que vêm de todas as leituras - feitas por membros das comunidades interpretativas de que fazemos parte - que se realizaram antes.

Para além dos textos escritos, qualquer criação simbólica é passível de leitura. Peter Burke, em sua obra Testemunha Ocular (2004), reflete sobre o uso das imagens como fontes históricas e testemunhos de uma época. Burke apropria-se de uma frase do historiador cultural Jacob Burckhardt para descrever imagens e monumentos como testemunhas do passado e como objetos "através dos quais é possível ler as estruturas de pensamento e representação de uma determinada época" (BURKE, 2004, p. 13).

No romance de Mia Couto, na parte que retrata a viagem do navio Nossa Senhora da Ajuda, observamos que as estruturas de pensamento dos portadores da imagem da Santa, os padres, continham intenções implícitas de dominação. Segundo D. Gonçalo, “A estátua de Nossa Senhora, benzida pelo Papa, é o símbolo maior desta peregrinação" (COUTO, 2006, p. 51). Nas mãos de Nimi Nsundi e, séculos depois, nas de Mwadia, a imagem tem sua significação alterada, revelando a estrutura de pensamento deles no contexto em que a leem. Diz Nsundi: "A minha Kianda, essa é que não pode ficar assim, amarrada aos próprios pés, tão fora do seu mundo [...] O meu pecado, [...] foi retirar o pé que desfigurava a Kianda [...] só peço que alguém mais [...] decida decapitar o outro pé da sereia" (COUTO, 2006, p. 208).

Há na imagem da Santa um encontro de culturas, pois o mesmo objeto sacro sugere diferentes leituras. Essa multiplicação de significações se dá como reposta à imposição da cultura ocidental europeia sobre a África nos tempos de colonização. Nos termos de Serge Gruzinski, ter-se-ia verificado nesse contato de culturas a "colonização do imaginário", caracterizada pela imposição de elementos simbólicos que sugerem ou ordenam a supressão de uma cultura por outra (GRUZINSKI, 2003). Sob essa ótica, as imagens sacras não seriam peças neutras ou meros ornamentos de igreja, e sim instrumentos de 
sujeição do universo cultural do colonizado pelo do colonizador. Todavia a complexidade do sincretismo religioso subverte essa ordem, pois aparentando acatar o universo imagético que lhes é imposto, os dominados procedem a isso leituras ressignificadoras. É um modo astuto de, pela via aberta pelo dominador, se preservar o mundo cultural que este rejeita.

No plano da ação presente, quando retorna a Vila Longe após ultrapassar o rio Mussenguezi, Mwadia Malunga sabia do espanto que sua chegada causaria e que "as vozes e os olhares the iriam certamente devolver a familiaridade perdida" (COUTO, 2006, p. 68). Mas ela não esperava encontrar sua antiga vila num estado tão decadente em decorrência da guerra ocorrida durante sua ausência. A igreja, na qual Mwadia intencionava abrigar a Santa, estava destruída. Assim o seu retorno é um mergulho em memórias e constatações de perdas pessoais e coletivas. É também um modo de visitar, sob o signo da crise, uma identidade possível em meio aos destroços paisagísticos e humanos com que se depara. De todo modo, Mwadia relê sua historia e sua condição em face da comunidade que reencontra.

Sua mãe, Constança Rodrigues, engordara e acusara a filha pelo seu aumento de peso, dizendo que desejava afogar a tristeza de sua partida se alimentando em excesso. Seu padrasto, que altera seu nome a cada aniversário, acreditando assim enganar a morte, agora se chama Jesustino. Sua tia Luzmina, irmã de seu padrasto, falecera e agora fazia parte da parede dos ausentes, onde eram fixadas as fotografias dos parentes falecidos para que não fossem esquecidos.

Casuarino, tio de Mwadia, chega à cidade e reúne os habitantes (entre eles, o barbeiro Arcanjo Mistura e o agente dos correios, Matambira) para comentar sobre a vinda de um casal de estrangeiros, o historiador afroamericano Benjamin Southman e a socióloga brasileira Rosie, que tinham o intuito de conhecer a verdadeira África e vinham recolhendo dados para a escrita de um estudo sobre o tema. Antevendo os possíveis lucros que viriam disso, Casuarino propôs que os habitantes forjassem histórias e memórias sobre a "verdadeira, primitiva e selvagem mãe África" para satisfazer o casal, pois eles se dispunham a pagar por isso, o que auxiliaria no desenvolvimento da vila: "Eles gostam de pagar [...] gostam porque sentem-se culpados [...] saíram daqui, deixaram a malta a sofrer com o colonialismo e, agora, regressam engravatados, cheios de inglesuras, e a gente ainda passando fome" (COUTO, 2006, p. 31).

Nesse ponto, o texto mostra como o relato da memória da comunidade pode ser seletivo e manipulado conforme os interesses envolvidos. Além disso, há por meio da ironia a desmoralização do estereótipo da "mãe África", uma construção ideológica ocidental vista como deslocada da realidade atual do continente e que nem sempre é leal ao modo como os próprios africanos consideram a sua cultura.

Fora decidido que Mwadia teria um importante papel nesse plano de seus conterrâneos, sendo a encarregada de encenar sessões de encarnação de espíritos antepassados. Mas, em um contexto de tantas falsificações, a "performance" de Mwadia é por demais comovente, amedrontadora e verossímil, surpreendendo a todos, até mesmo aos que sabiam do plano, chegando esses a se indagar se ela estaria sendo possuída de verdade por espíritos. Mwadia parecia ter incorporado o espírito do escravo Nimi Nsundi, deixando os americanos estarrecidos. Benjamin observa que tudo o que ela falava correspondia à realidade histórica estudada por ele. Mas o que ninguém sabia era que essa atuação de Mwadia era induzida pela sua leitura.

Durante o dia, ela lia os documentos de D. Gonçalo da Silveira que encontrara junto à Santa e, durante a noite ia ao quarto do casal de historiadores visitantes para ler seus papéis, além de visitar a biblioteca do padrasto. Para Mwadia, a leitura desses textos e a ressignificação dada a eles, junto com a leitura da simbologia da Santa e sua história - que é a complexa ponte espiritual e cultural entre os anseios de dominação dos colonizadores e a luta de resistência dos colonizados - é o que proporciona o confronto com a memória de seu povo e dá sentido à viagem que fez de Antigamente a Vila Longe.

Chama a atenção, contudo, o modo como o texto do romance é inconclusivo e propositalmente ambíguo no que diz respeito à participação da protagonista na aparente "encenação" feita para os visitantes estrangeiros. Se, por um lado, ela aparenta fazer um uso calculado dos conteúdos lidos a fim de construir a dramatização do escravo supliciado pelos navegadores por adorar a Santa como se ela fosse uma Kianda (sendo ele, nesse sentido, o símbolo crítico do suplício do continente africano pela violência do colonizador), por outro lado, evocar a memória de Nimi Nsundi e sua relação com a Santa é um modo de Mwadia retornar ao caminho da sua espiritualidade familiar e tribal, abandonada anos antes, desde quando saiu de sua comunidade para estudar em um colégio cristão no Zimbábue. De fato, ela sente-se escolhida pela divindade das águas para ser uma nyanga, uma sacerdotisa. Durante muito tempo ela abdicou de seu destino seguindo o Cristianismo. Mas ironicamente, é ao encontrar uma Santa católica, pela forma como se dá a "leitura" sincrética da imagem, que sua verdadeira vocação aflora. Deve-se levar em consideração que é recorrente em várias religiosidades africanas a crença de que os mortos continuam a afetar a vida dos vivos, e que os espíritos são parte da família e representam a ancestralidade, e os nyangas são os agentes principais para a validação dessas crenças, sendo também os que incorporam os antepassados falecidos. 
Seja como for, a partir da viagem, pelos caminhos da memória e da leitura, opera-se para Mwadia um encontro com o passado e com suas tradições, o que a leva a (re)descobrir o que é a sua verdadeira vocação: ser a ligação entre os mundos. A protagonista faz uma descoberta:

Nesses últimos dias, Mwadia fechava-se no sótão e espreitava a velha documentação colonial. Agora ela sabia: um livro é uma canoa. Esse era o barco que lhe faltava em Antigamente. Tivesse livros e ela faria a travessia para o outro lado do mundo, para o outro lado de si mesma (COUTO, 2006, p. 238).

\section{Identidade relida}

A capacidade leitora e a oralidade (presente no modo como oferece à comunidade o que leu) fez com que Mwadia cumprisse o que anuncia o significado de seu nome. Como canoa, ela liga, pelo ato leitor, dois mundos, dois povos, duas culturas, duas histórias, revisitando e reconstruindo o passado para descobrir a si mesma e movimentando a memória coletiva entre os seus com a importante função de contribuir para o sentimento de pertencimento a um grupo de passado comum.

É certo que isso não a livra da percepção de uma ausência de soluções para os problemas de sua comunidade no presente. Sem encontrar um lugar seguro para o repouso da imagem da Santa, Mwadia é aconselhada por Arcanjo Mistura a deixar Vila Longe. Arcanjo também pondera que Mwadia nunca encontrará uma igreja para a Santa, pois mesmo havendo igreja, faltava crença.

O barbeiro explicou-se: ele seria um crente, sim, no dia em que a igreja morasse perto de cada um. Em miúdo, tal como Mwadia, deixara-se encantar pela solenidade dos rituais. Mas depois a igreja perdera tudo isso: em nome de um maior contacto com a gente perdera-se o contacto com o divino.

- É o que digo, Mwadia: não leve essa Virgem para nenhuma igreja.

- Levo para onde?

- O que tem a fazer é o inverso do que tem feito: deixar que a Santa a conduza a si, ela é que anda procurando um lugar seguro para si (COUTO, 2006, p. 318).

Pelo que é expresso em $O$ outro pé da sereia, percebemos que a viagem de Mwadia às voltas com a procura de um lar para a Santa é também o que desencadeia o reencontro com suas origens. Mais do que reencontrar uma religião, a forma como ressignifica a imagem a faz voltar às suas raízes moçambicanas e africanas, carregando o fardo (mas também a honra) de pertencer a uma terra de tantas contradições. A viagem de volta para Vila Longe reconstrói sua relação com sua comunidade. Mas, além disso, ela revê o passado de Moçambique por meio do que a leitura lhe oferece.
Renova-se a sua vocação de ser uma canoa que liga os tempos e as culturas, compreendendo o impacto do que, no choque de culturas entre colonizador e colonizado, subsiste como hibridismo e mútua transformação. Acrescente-se que, sendo a encarnação da canoa, Mwadia projeta-se (a ponto de viver uma plena dramatização) na figura de um escravo, Nimi Nsundi, cujo culto sincrético à imagem de Nossa Senhora ocorre - em um ato de transgressão - durante uma viagem de navio, uma nau de exploração colonial. Desse modo, na vivência leitora e memorialística da protagonista os símbolos aquáticos e náuticos assumem uma grande e intensa força poética que sinaliza tanto para elementos vitais como para a perdição, o desconsolo e a resistência.

Voz africana e lusófona destacada, Mia Couto é um escritor relevante no cenário da literatura mundial contemporânea porque os temas abordados em seus livros são, sim, os de sua aldeia, mas também são universais.

\section{Referências}

BURKE, Peter. Testemunha ocular: história e imagem. Bauru: EDUSC, 2004

COMPAGNON, Antoine. O demônio da teoria: literatura e senso comum. Belo Horizonte: UFMG, 2010.

COUTO, Mia. O outro pé da sereia. São Paulo: Companhia das Letras, 2006.

GRUZINSKI, Serge. A colonização do imaginário. São Paulo: Companhia das Letras, 2003.

HALBWACHS, Maurice. A memória coletiva. São Paulo: Centauro, 2006.

JOUVE, Vincent. A leitura. São Paulo: Unesp, 2002.

KESSEL, Zilda. Memória e memória coletiva. Disponível em: <http://www.museudapessoa.net/adm/Upload/291I 6110920121916535P032.pdf>. Acesso em: 20 out. 2012.

LAJOLO, Marisa; ZILBERMAN, Regina. A formação da leitura no Brasil. São Paulo: Ática, 1996.

LOPES, José de Souza Miguel. Cultura acústica e cultura letrada: o sinuoso percurso da literatura em Moçambique. (in) Contatos e ressonâncias: literaturas africanas de língua portuguesa. Belo Horizonte: PUC Minas, 2003.

PARADISO, Silvio Ruiz. A Imagem do Feiticeiro Pós-Colonial em Mia Couto. Anais do 4o CIELLI, Maringá, jun. 2010.

ROSSI, Paolo. O passado, a memória, o esquecimento: seis ensaios da história das ideias. São Paulo: Unesp, 2010.

WEINHARDT, Marilene. Ficção e história: retomada de antigo diálogo. Revista Letras, Curitiba, n. 58, p. 105-120. jul./dez. 2002.

Recebido: 05/06/2018

Aprovado: 12/12/2018

Autores:

MARCELO FRANZ

mfranz4390@gmail.com

VICTOR DE BARROS RODRIGUES

victorbarrosbr@gmail.com 